\title{
Citizen Science and Biomedical Research: Implications for Bioethics Theory and Practice
}

\author{
Chris William Callaghan \\ School of Economic and Business Sciences, \\ University of the Witwatersrand, Johannesburg, South Africa
}

\section{Chris.Callaghan@wits.ac.za}

\begin{abstract}
Certain trends in scientific research have important relevance to bioethics theory and practice. A growing stream of literature relates to increasing transparency and inclusivity of populations (stakeholders) in scientific research, from high volume data collection, synthesis, and analysis to verification and ethical scrutiny. The emergence of this stream of literature has implications for bioethics theory and practice. This paper seeks to make explicit these streams of literature and to relate these to bioethical issues, through consideration of certain extreme examples of scientific research where bioethical engagement is vital. Implications for theory and practice are derived, offering useful insights derived from multidisciplinary theory. Arguably, rapidly developing fields of citizen science such as informing science and others seeking to maximise stakeholder involvement in both research and bioethical engagement have emerged as a response to these types of issues; radically enhanced stakeholder engagement in science may herald a new maximally inclusive and transparent paradigm in bioethics based on lessons gained from exposure to increasingly uncertain ethical contexts of biomedical research.
\end{abstract}

Keywords: biomedical ethics, citizen science, informing science, probabilistic innovation, crowdsourcing, transparency, scientific inclusiveness

\section{Introduction}

Given increasing importance of disclosure and transparency issues in contemporary bioethics literature, this paper argues that at the heart of the concept of ethical practice itself is the notion of transparency toward stakeholders. Relevant to this principle is emergence of new citizen science (CS) methodologies (Bonney et al., 2009), including public participation in scientific research (PPSR) (Shirk et al., 2012), participant-led biomedical research (PLR) (Vayena \& Tasioulas, 2013), and novel scientific ethics theory development such as that associated with post-normal science (Funtowicz \& Ravetz, 1994). This body of literature, which extends stakeholder theory

(CC BY-NC 4.0) This article is licensed to you under a Creative Commons Attribution-

NonCommercial 4.0 International License. When you copy and redistribute this paper in full or in part, you need to provide proper attribution to it to ensure that others can later locate this work (and to ensure that others do not accuse you of plagiarism). You may (and we encourage you to) adapt, remix, transform, and build upon the material for any non-commercial purposes. This license does not permit you to use this material for commercial purposes.
(Freeman, 1984), may be forming the basis for a new model of ethics in science, which may offer important trend insights for bioethics theory and practice.

Parallel to these changes arising from citizen science movements dedicated to the democratisation of science are new ethical imperatives that have emerged in the wake of global societal crises, such as the Ebola virus disease epidemic, which have effectively "demanded the reinterpretation of long- 
standing ethical principles under extreme and urgent circumstances" associated with the need for real time emergency response (Fenton, Chillag, \& Michael, 2015). Convergence of citizen science principles of transparency and stakeholder engagement in biomedicine is therefore occurring together with emergent recognition of the need for radically improved temporal responsiveness to urgent needs, which arguably places bioethics at the center of debates concerning these developments. Guidance on how to negotiate these changes and evolving needs requires bioethical guidance and leadership robust to extreme change and uncertainty related to technologically enabled breakthroughs in biomedical research.

This paper, therefore, seeks to relate emerging citizen science movement theory to certain extreme examples of biomedical science, such as increasing global trade in human tissues and the dramatic breakthrough potential of genetic engineering. On the basis of this synthesis, useful insights are derived, and two models are developed, of (i) how divergence in industrial versus knowledge paradigms on the basis of a knowledge revolution potentially drives a new ethics of connectivity and maximized stakeholder engagement, and of (ii) 'first level' theory recommendations that are related to 'second level' practice recommendations for bioethics. Knowledge of these changes is considered particularly important in a global context vulnerable to crises such as Ebola, Zika, and dramatically increasing antibiotic resistance, for example, where such threats are one side of the bioethical engagement equation, while on the other are dramatic developments in biomedicine that might require radically increased transparency and ethical scrutiny. Such arguments are considered particularly salient as the field of bioethics, notwithstanding its foundation in moral philosophy as well as its incorporation of multidisciplinary roots, as it moves towards specialization (Grady, 2013; White, Jankowski, \& Shelton, 2014) and the need to harness benefits of specialism while at the same time taking into account the rise of scientific democratization.

Bioethics has been considered a 'movement' originating in response to "profound moral questions arising from burgeoning innovations in medicine and concerns about abuses in human subjects research" (Tartzian, Wocial, \& The ASBH Clinical Ethics Consultation Affairs Committee, 2015, p. 38), and a trend within certain areas of this literature has been to "engender spirited academic debate and invite broader public conversation" (Magnus, Parsi, \& Sharp, 2014, p. 1). On the basis of synthesis of certain literature (and rationales), this paper seeks to derive a model useful for medical and bioethics practitioners, which is both informative and offers a projection of trajectories of development of this research as it may intersect with medical practice and research.

Arguably, engagement with this developing literature is important for the following reasons. First, in a context associated with the "breakneck pace of genome-technology development" and dramatic advances in fields of science underlying medical research, which have "revolutionised bioscience research" (Hayden, 2014, p. 294), at the same time a pharmaceutical drug development process exists that "has remained virtually unchanged for nearly 50 years," and is "slow, inefficient, risky and expensive" (Kaitin, 2010, p. 356), and where new drugs approved per US dollars spent on R\&D "has halved roughly every 9 years since 1950, falling around 80-fold in inflation-adjusted terms" (Scannell, Blanckley, Boldon, \& Warrington, 2012:191). Relatively slow pharmaceutical innovation faces a challenge in the form of increasingly disruptive global innovative capacity, and its potential to provide curative solutions and disrupt chronic markets, for example such as those for HIV drugs (that has a market value of about $\$ 11.9$ billion for example in 2013, projected to rise to $\$ 17.3$ billion in 2020) (Datamonitor Healthcare, 2014). Unresolved tensions between medical profit-prioritisation and its patterns of exclusion of impoverished populations requires theory development to find a way forward, and it is argued the trajectory of democratisation of science offered by citizen science and its related movements may offer useful insights into causal mechanisms of change and how current inequalities in medical science provision may be addressed by greater connectivity of populations and stakeholder activism. 
Second, it is possible that societal costs of the absence of a moral imperative to focus on curative medicine are compounded by a fundamental change in the nature of pharmaceutical R\&D (Scannell et al., 2012). Pharmaceutical R\&D is arguably at the end of a 'low hanging fruit' era (Scannell et al., 2012) associated with small molecule drug development, and the field has moved into the big molecule protein-based drug development era (Lim \& Suh, 2015). This paradigmatic change has perhaps put added pressures on drug firms to cling to their most profitable options to ensure survival and continued profitability. Shift in structures of medical innovation to biological, or large molecule products (Lim \& Suh, 2015) poses serious questions about the closed models of innovation primarily benefitting from small molecule innovation, particularly in the face of challenges from the successes of open innovation (Chesbrough, 2011). It is argued here that open and probabilistic innovation enabled by recent technological advances are essentially underpinned by an emerging ethical philosophy associated with the literature of CS (Bonney et al., 2009), PPSR (Shirk et al., 2012) and PLR (Vayena \& Tasioulas, 2013), for the reason that both open innovation and the epistemological roots of this literature relates to what are arguably the same causal channels. These causal channels are considered to be associated with the rise of technologicallyenabled connectivity and the emergence of Internet technologies, crowdsourcing, and social media that allow for high volume data collection, synthesis, and analysis using the 'crowd.' However, increased connectivity has also enabled the potential for increased scrutiny of science (Funtowicz \& Ravetz, 1994) and has perhaps empowered populations and a power shift toward democratisation of science. Given radical changes in biomedicine and the need for increasing bioethical engagement (Grady, 2013), these changes may herald a new era in biomedical ethics, and knowledge of these trends is arguably important for practitioners as well as theorists.

Having outlined certain arguments made in this paper, these arguments are now located in relation to extreme examples from the medical ethics literature. By doing this, key issues at the nexus of citizen science and medical ethics are highlighted. First, examples of trade in human ova within an increasingly globalised context of commercialisation of human tissues are discussed, and secondly, advances in genetic engineering are considered, representing a research context characterised by rapidly increasing uncertainty that arguably requires maximally inclusive and transparent bioethical engagement and response. Trade in human tissues is now discussed.

\section{Commercialization of Human Tissues}

The 2009 New York Stem Cell Foundation (NYSCF) ethics committee decision to allow payment for research eggs, although based on the rationale that US federal law allows payment for human ova in fertility treatment (in vitro fertilisation (IVF)), has been criticised (Dickenson, 2009) as the practice essentially derives from a loophole in the US Anatomical Gift Act of 1987 barring payment for organs but not for gametes (in the form of eggs and sperm) due to their classification as renewable tissue.

In terms of stem cell research, human eggs are typically used for somatic cell nuclear transfer (SCNT), a process in which an adult cell is fused with the egg to achieve a tissue match to a donor; however, this process requires large volumes of eggs (Dickenson, 2009). Some have argued that in light of the health risks of egg production and the risk of ovarian hyperstimulation syndrome, payment for eggs is justified and it is unjust and exploitative not to pay, yet the US National Academies of Science guidelines stipulate only reimbursements, cash or in-kind, should be allowed for oocyte donation for research; in contrast, the US state of California forbids payment for eggs in research and the European Union does not allow the sale of eggs for IVF but research is exempted (Dickenson, 2009).

Given the role of private medicine, bioethics also overlap with business ethics, and at the extreme interface between business ethics and medical ethics are notions and legislative engagements that seek to balance increasingly complex stakeholder rights. A need for development of codes of bio- 
ethics (Tartzian et al., 2015) reflects increasing complexity of issues in the field of bioscience. Historically, "codes of ethics for health care organisations had been written by elite members and imposed on their membership by authority or guile" as in the case of the American Medical Association's (AMA) first code of medical ethics, but the trend has been to become more inclusive (Baker, 2015). A core argument of this paper, however, is that a radically comprehensive process of stakeholder engagement, which extends to all potential stakeholders (akin to the broad societal movements that have manifested in the form of citizen science, public participation in scientific research, participant-led research and probabilistic innovation, or crowd-based engagement in research) is required to complement bioethics theory and practice, and can assist to provide ethical direction to medical research that minimises potential externalities associated with constraints to the research process. To some extent, however, it can be argued that this broad stakeholder engagement already exists as a consequence of the democratic process, and that policy can shape biomedical research in this way. However, more democratic responsiveness may be necessary in a world in which disasters can occur in real time, requiring real time bioethical response. The extreme examples used here seek to illustrate problematic issues and to support arguments for a more inclusive engagement by stakeholder populations with issues at the nexus of medical research and business ethics.

Other techniques (such as those based on induced pluripotent stem cell (iPSC) research do not use eggs, but instead use adult somatic cells reprogrammed to attain a pluripotent state) received preferential funding by the Obama administration at the expense of SCNT research because of the dangers associated with egg donation; this diversion of funding received bioethicist support (Dickenson, 2009). This channel of ethical transmission (from stakeholder engagement via democratic process toward biomedical research), however, might be at the mercy of the political process, and thus may lack the direct ethical engagement offered by processes that maximise stakeholder participation in ethical decision making. Political decisions by this president and his predecessor, instead of bioethics leadership, therefore had an impact on the biomedical landscape. It seems it would be within the power of future presidents to sway biomedical research.

Other bioethical issues relevant to commercialisation of human tissues relate to international justice. For instance, the 2006 International Society of Stem Cell Research guidelines have sanctioned payment for eggs for research but prohibit eggs produced under IVF to be used for research; this system, however, can lead to a two-tiered system that disadvantages those in developing countries but protects health of those in developed countries (who are more likely to be undergoing IVF) (Dickenson, 2009). International differences in legal capacity add to decision making complexity and regulation dilemmas; these uncertainties and complexities reflect uncertainties considered by post-normal science relating to environmental and ecological research, which require extensive engagement of all stakeholders on a scale sufficient to be able to reach a deep and unmitigated ethical interrogation of decisions (Funtowicz \& Ravetz, 1994). Professionalization of bioethics and education (White et al., 2014) needs to also be responsive to democratisation of science, although the bioethics field is trending from diversity in backgrounds of bioethicists toward greater specialisation in training (Grady, 2013).

Crowd-based ethical engagement may offer an 'anchor' to ethical decision making in contexts of uncertainty and complexity, as it in principle stresses the inclusiveness and transparency of stakeholder engagement in decision making. This type of ethical anchor might be necessary in a global context where market and bioethics interactions are increasingly pervasive. Issues relating to the commercialisation of the human body are examples that stress the importance of bioethics as a conceptual partner to corporate involvement in biomedicine.

Dickenson (2009) argues that the sale of human tissue represents the commercialisation of the human body. In the wake of the 1973 US Supreme Court Roe v Wade decision, which legalised abortion, the US government refused funding for embryo research, for fear of encouraging abor- 
tions; President George W Bush prohibited federal funding for stem cell research from 9 August 2001 onwards, but allowed federal funds to be used on stem cells derived before this date (Wertz, 2002). Arguably, the future potential of further political decision making to influence bioscience adds to already increasing intractable complexity and social forces that interact at the nexus of biomedical science; this plurality of perspectives is potentially problematic if theory is not developed to address these challenges.

Funtowicz and Ravetz (1994, p. 1881) contrast Kuhn's (1962) notion of 'normal science' (relating to research aimed at solving problems which are assumed to have answers) to that of 'nonnormal' science, which relates to problems inextricably related to "unpredictability, incomplete control, and a plurality of legitimate perspectives." These instances echo Rittel and Webber's (1973) notion of 'wicked' problems posed by values and social complexity, differentiated from the 'tame' problems characterising natural science in general. Notwithstanding potential for legal intervention in biomedicine, the legal intricacies around sale of human tissues offers a useful example of this paradigm.

The refusal by the US government to fund stem cell research, however, was not independent of cultural background and religious beliefs as well as ethical issues (Wertz, 2002). Given the complexity of the interactions between these forces, explicit mechanisms are perhaps needed, which can solicit stakeholder inputs from a wide and diverse enough set of constituents, particularly in an increasingly globalised context. Such mechanisms might ensure that all voices are given a hearing; taking recourse to the crowd through explicit engagement with it might offer an important forum, offering legitimacy advantages for policy decisions. Funtowicz and Ravetz (1994, p. 1882) explain the principles of post-normal science as offering an extension of legitimacy, especially in contexts of policy dialogues, when problems exist in which "facts are uncertain, values are in dispute, stakes are high, and decisions urgent." The notion of the 'crowd' takes on another dimension when the globalised nature of decision making in business and medicine is considered.

The US context is but one dimension of global practice in medical ethics. Literature has also been critical of the dominant paradigms in ethics, led as they are by US and European values and principles. Examples of this criticism can be found in terms emerging in this literature. Abstractness in bioethics is a term used to express the "tendency for 'Western' bioethics to become excessively technical and legal" as some "have argued that respect for values, symbols, and social meaningfulness of medicine and ethics in different societies requires making principles that are practical in those societies" (Döring, 2003:238). Framing ethics in terms of externalities or costs to populations might be helpful. Externalities or costs and benefits to populations of ethical decision making, Western or not, arguably necessitate inclusion of the community in scientific decision making, according to the tenets of post-normal science.

The "dynamic of resolution of issues in post-normal science involves the inclusion of an evergrowing set of legitimate participants in the process of quality assurance of the scientific inputs..." and "the establishment of the legitimacy and competence of participants will inevitably involve broader societal and cultural institutions and movements" (Funtowicz \& Ravetz, 1994, p. 1885). According to this perspective, bioethical scrutiny is also a function of communities, and transparency and accountability are also functions of populations affected by the research, which is considered to be necessary given the complexity of issues.

The principle of a-historicism relates to a "trend in 'Western' bioethics towards an ethics of convenience, which does not acknowledge the historical context of individual communities" (Döring, 2003, p. 238). The history of paradigms of social science (Burrell \& Morgan, 1979) reflects perhaps the power of history to shape social science assumptions, and bioethics is seemingly no different. For Latour (2000, p. 117) one has to understand the "divides between nature and society, 
necessity and freedom, between the relevant domain of the natural sciences and the social sciences, as a very peculiar anthropological and historical feature" as one:

has simply to look at any of the quasi-objects flowing nowadays through our newspapers from genetically modified organisms to global warming or internet commerce, and be convinced it might be about time for social and natural scientists to forget about what separates them and start looking at those 'things' whose hybrid nature has, for many decades now, already unified them in practice.

Latour (2000, p. 17) considers this "new political situation" a golden age for the social sciences. What seems clear from this is the argued need perhaps for a re-evaluation of differences between the sciences and a new focus on understanding phenomena from inclusive perspectives. Ahistoricism is problematic, as it also suggests lack of reflexivity. Without reflexivity and a keen sense of history, science can perhaps take a dystopian path, as evident in history of the World Wars, where industrialised and mechanised science facilitated destructive ideologies and agendas.

In terms of bioethics, however, the divergence between 'Western' versus 'non-Western' principles and philosophies of biomedical ethics does not represent the whole story; differences also exist between the Anglo-American context and its European counterpart. In terms of contemporary medical ethics, the concept of autonomy as political principle and as philosophical concept are interpreted differently in Anglo-American versus European contexts, the former taking a libertarian stance associated with self-determination and the latter a deontological, or duty-based ethical stance associated with self-governance (Döring, 2003, p. 238). For Mandal, Ponnambath, and Parija (2016, p.5) deontology is patient-centred, whereas utilitarianism is "society-centred" yet whereas these approaches contradict each other, as ethical approaches they need to be balanced. Ethical codes for bioethics (Baker, 2015; Tartzian et al., 2015) that incorporate citizen science and post-normal ethical principles might maximise transparency and accountability.

The challenge seems to be to unite conceptions of bioethics across contexts and societies, and hence the need for overarching theory in contexts of debates characterised by increasing complexity. Problem solving, which is typically dependent on interactions of epistemic (knowledgebased) and axiological (values-based) aspects, is beset by systems uncertainties that are uniquely suited to the problem solving methods of post-normal science (Funtowicz \& Ravetz, 1994, p. 1882), explained as follows.

The term "systems uncertainties" conveys the idea that the problem is concerned not with the discovery of a particular fact (as in traditional research), but with the comprehension of management of a reality that has irreducible complexities and uncertainties. By "decision stakes" we refer to all the various costs, benefits, and value commitments that are involved in the issue through the various stakeholders...For a simple example, we may consider dams. For a long time the location and design of dams had been seen as essentially a problem in applied science; given the needs of flood control, water storage, or irrigation, the design exercise was straightforward. Systems uncertainties could be managed scientifically, and decision stakes were those of the policymakers. With the emergence of disputes over policies for the use and conservation of water, it became clear that professional consulting was involved. The decision stakes were now part of the political process, and the various corporate interest groups employed their own experts to assist in the debate. But now that the whole rationale of dam-building is being questioned, with uncertainties and criticisms on all fronts from the hydrological to the social and religious, we are in the realm of postnormal science.

These perspectives offer challenges to the biomedical ethics literature as it seeks common ground to develop a deeper theoretical framework. It is argued here that the citizen science movement, or crowd-based engagement, offers a social movement (Callaghan, 2015) that may over time in- 
crease transparency and accountability in biomedical practice. Another useful example of the increasing complexity of business/biomedical ethics is the case of gene-transfer and genetic engineering in relation to human biomedical research.

In particular, the new ethical philosophy of post-normal science, with its genesis in expert environmental research conflicts, stresses comprehensive stakeholder engagement as a mechanism to ensure quality control and legitimacy of expert research (Funtowicz \& Ravetz, 1994). Together, these literatures seem to suggest a new paradigm in medical ethics, at the heart of which is maximised stakeholder involvement in ethical decision making and maximising transparency, termed 'crowd-based ethics'. The crowd represents all possible stakeholders, an 'open' model of ethical engagement which seeks to maximise inclusiveness in ethical decision making, especially under certain conditions that are explicitly considered by this body of literature.

\section{Genetic Engineering}

The first gene-transfer ("application of genetic sequences or genetically modified organisms to human beings for investigational or therapeutic ends") trial in humans was conducted over two decades ago; certain ethical issues, however, remain unresolved, such as those related to (i) when it is appropriate to begin human testing, (ii) the acceptability of germline modification itself, and (iii) whether germline modification should be applied to augment traits, which are issues perhaps not easily resolved by taking recourse to precedent on account of scientific uncertainty associated with gene transfer and the social context of innovation itself (Kimmelman, 2008, p. 239). Arguably, codes of bioethics (Baker, 2015; Tartzian et al., 2015) are currently ill-equipped to deal with the increasing complexity of these issues.

Clustered regularly interspaced short palindromic repeats (CRISPR) technology now offers potential editing of the human germline (O'Keefe et al., 2015). Genetic engineering technology is expanding globally. By 2008, more than 1300 human gene-transfer clinical studies were registered on the Journal of Gene Medicine database; since then China has licenced the first genetic medicines, and gene transfer has become standard care for certain immunological disorders (Kimmelman, 2008). In such a rapidly developing field a consideration of emergent business/biomedical ethical issues is particularly salient. Arguably, citizen science networks are increasingly important in order to increase the democratisation and transparency of the scientific process and expose issues on which decision making and regulatory processes will build, as these conditions reflect post-normal scientific conditions of uncertainty and complexity (Funtowicz and Ravetz, 1994). According to Funtowicz and Ravetz (1994, p. 1885):

The scientific process now encompasses the management of irreducible uncertainties in knowledge and ethics, and the recognition of the complexity, implying the legitimacy of a plurality of perspectives and ways of knowing. In this way, its practice is becoming more akin to the workings of a democratic society, characterized by extensive participation and toleration of our diversity. As the political process now recognizes our obligations to future generations, to other species, and indeed, to the global environment, science also expands the scope of its concerns. We are living in the midst of this transition, so we cannot predict its outcome. But we can help to create awareness and also the intellectual tools whereby the process of change can be managed for the best benefit of humanity and the global environment.

Genetic engineering innovation, with its 'irreducible uncertainties' is an example of research that is not typical of other biomedical research due to its high levels of uncertainty; on this basis it is argued that a new paradigm in business/biomedical ethics is needed in order to radically increase inclusiveness of inputs into the ethics decision making process. Current ethical processes might 
have reached their limit. The 1982 US President's Commission for the Study of Ethical Problems in Medicine and Biomedical and Behavioural Research concluded genetic engineering applications should be judged by general ethical standards and procedures; the implication of this is that somatic gene transfer (sGT) and similar techniques were at the time considered to be of a similar nature to other novel medical research developments (Kimmelman, 2008). Other examples of genetic research which require special attention (and an arguably a new paradigm of citizen science transparency and engagement) are considered briefly as follows.

Assessment challenges of risk and uncertainty are reflected in tragic incidences of mortality in early phase gene transfer clinical trials related to attempts to treat ornithine transcarbamylase deficiency and severe combined immunodeficiency (X-SCID), the latter involving resultant leukaemia (Kimmelman, 2008). Arguably, these treatments require novel conversations around bioethics, and arguably the increasingly 'open' and more 'inclusive' paradigm of scientific research (and its related ethics paradigm) may ultimately supplant closed models of innovation and scientific R\&D (Chesbrough, 2011), as well as their relatively less inclusive forms of ethical decision making. The new paradigm of open innovation is perhaps also trending towards an open and inclusive model of ethical engagement. The trend toward 'openness' in scientific research (and in its ethical and quality review process) is itself increasingly prevalent (Vayena \& Tasioulas, 2013, p. 787), reflected as it is in the rise of movements such as PLS, but, importantly, this trend entails a change in oversight criteria and methods of implementing them:

Open and wider review of research projects, data and scientific papers is a growing trend. It responds to urgent needs for greater transparency as to how scientific evidence is generated, for cost containment and for swifter translation of research into applications. PLR's most valuable feature may well be this very openness. It is vital to capitalise on it in order to ensure both scientific rigor and ethical soundness. If PLR is to earn its place in the biomedical enterprise, it must comply with ethical values. Stakeholders in biomedical research engaged in exploring the potential of innovative research models need also to think creatively about research governance and oversight. The beginning of wisdom is that responsiveness to the same underlying values is not best secured by a one-size-fits-all model of ethical oversight. Unless we explore new oversight criteria, and the means of implementing them, we risk losing the manifold benefits promised by PLR.

Notwithstanding the fact that risk levels of gene transfer trials compare favourably in relation to typical cytotoxic drugs used in cancer treatment, gene transfer trials are associated with higher uncertainty (Kimmelman, 2008). For instance, SCID research dangers were unanticipated, due to the unsophisticated state of the animal models and toxicology assays used for preclinical safety assessments; another trial, with almost identical conditions to the one associated with adverse effects, was successful in reversing the disease without the emergence of identifiable malignancies, although these have been reported to be more likely to occur with time (Kimmelman, 2008). When consensus between experts is required for problem solving, particularly in instances where historical or field data are inadequate for models of hazards, and disagreement exists between experts, "the task of quality assurance is then conducted at a higher level, namely the assessment of the quality of the experts themselves" yet such a process "could iterate without end," leading to the "expertise problem" (Funtowicz \& Ravetz, 1994, p, 1883). Issues related to SCID research and treatment are especially problematic in the absence of a widely accepted system for quantifying risks (Kimmelman, 2008).

Another issue in genetic research is when it is appropriate to begin human trials. Clinical equipoise, or the uncertainty of the medical community as to the therapeutic benefits of different agents in clinical trials, offers certain guidelines but is less helpful in this type of largely exploratory (Phase 1) research, particularly in the absence of a coherent framework that includes stake- 
holders such as researchers, policy makers, patient advocates, or ethicists (Kimmelman, 2008). According to the post-normal science perspective, individuals directly affected by problems can perform a function "analogous to that of professional colleagues in the peer-review or refereeing process in traditional science, which in their absence might not occur in these contexts" and therefore "post-normal science requires an extended peer community, participating in quality assurance and the problem-solving process, for its proper functioning" (Funtowicz \& Ravetz, 1994, p. 1885). Maximising the scale of stakeholder engagement and transparency may make conflict between agendas explicit, and increase representivity.

The Declaration of Helsinki, an ethics code, requires any clinical study to have a "favourable balance of risks and possible benefit" with two categories of benefit, namely (i) to the human volunteer (therapeutic value) and (ii) for society (scientific value); this principle, however, excludes instances where clinical and scientific objectives conflict, "as they often do" (Kimmelman, 2008, p. 240). Bioethics codes (Baker, 2015; Tartzian et al., 2015) proliferation should perhaps explicitly seek to broaden stakeholder engagement, which might be a necessary albeit not a sufficient condition for better management of these challenges. Kimmelman (2008, p. 240) questions how clinical and scientific objectives can be better balanced, arguing the key to answering this question "is in ensuring that diverse stakeholders are represented in risk deliberations" as, for example, researchers, and ethics committees might "solicit input from research and patient advocates, or the broader scientific and clinical communities" in addition to full publication of preclinical studies before trial initiation. O'Keefe et al. $(2015$, p. 3) stress that because "the metaphors around CRISPR are still in the formation stage, we advocate for a multidisciplinary conversation among scientists, bioethicists, and academics studying cognition, linguistics, and rhetoric to begin exploring possibilities for metaphors which adequately capture the complexity of ethics issues involved in CRISPR." Increasing transparency and maximising engagement with these issues may make it less likely for public information channels to be manipulated.

Maximising transparency and stakeholder engagement might not be a 'magic bullet' solution but in the face of rapidly increasing uncertainty and complexity, the post-normal science theoretical framework (Funtowicz \& Ravetz, 1994) and the citizen science (Shirk et al., 2012) approach might offer useful insights in attempts to manage an increasingly ethically-fraught area of science. Three aspects of biotechnology in particular need to be conveyed to an informed public, namely knowledge of (i) the ethical complexity of the technology, (ii) accurate descriptions, including how it works and its uses, and (iii) explicit knowledge of exactly what is known and what is not known about potential consequences (O'Keefe et al., 2015).

The nexus of business and biomedical ethics is populated with a diversity of contextual issues that may make a stakeholder approach imperative, given the absence of an alternative paradigm to explicitly maximising engagement. The intensity of contextual pressures upon decision makers will surely not decrease over time in the business-ethics/medical-ethics 'space'. Kimmelman (2008, p. 240) stresses the importance of contextual issues in ethical decisions in genetic research:

Another set of ethical challenges in translating gene transfer, as with other novel medical interventions, concerns the social and economic milieu of research. Many early phase gene-transfer trials bring together a potent mixture of desperately ill research subjects, ambitious (and sometimes financially invested) clinical champions, biotechnology firms, engaged disease advocates and news media. These factors have at times produced a turbulent dynamic in which concepts are rushed into trials, preclinical and clinical results are oversold, research efforts are fragmented and adverse events go underreported.

Patient advocacy groups and citizen science representation can provide transparency, as well as a much-needed legitimacy; this particularly important given the widening divergence between 
precedent in biomedical research relating to a paradigm of certainty, versus a new paradigm of uncertainty associated with genetic engineering and other research, given that this research is also surely eyed by drug firms as the next potential source of windfall profits, following the end the small molecule paradigm (Scannell et al., 2012). Challenges in conveying knowledge of bioethical issues to an informed public (O'Keefe et al., 2015) can draw on research with an express focus on informing stakeholder groups, such as work in the area of informing science (Cohen, 1999; Gill \& Cohen, 2009).

The citizen science movement (Irwin, 2001; Shirk et al., 2012) covers similar ground to other movements that overlap in their focus on inclusiveness of access to information and importance of stakeholders. Informing science, as a field, seeks to improve efforts to inform clients, or provide them with information in a form, format, and schedule that maximises effectiveness (Bednar \& Welch, 2008, 2009; Cohen, 1999; Gill, 2009a). Such a focus can be particularly important for areas of biomedical research that typically escape scrutiny and ethical engagement of those potentially affected by advances, as well as those potentially affected by lack of innovativeness.

The informing science movement, therefore, exists as a transdiscipline focused on the informing system as unit of analysis, or processes and channels devoted to a particular need to inform stakeholders (Gill \& Cohen, 2009). A transdiscipline in this instance relates to fostering collaborations amongst researchers across disciplines, which requires an extension of the notion of what constitutes 'research' itself, in terms of developing theory (Gill, 2009b) around the general problem of 'informing.' Whereas citizen science incorporates populations in pursuit of science (Irwin, 2001; Shirk et al., 2012), informing science seeks to address problems whereby different disciplines duplicate efforts while studying the same types of issues, and typically end up creating 'silos' and constraining effective knowledge creation (Gill \& Cohen, 2009). Such practices can be problematic in 'high stakes' areas of science such as genetic engineering and the opening up of commercial markets for human tissues. In informing citizen crowds of developments in science which can affect them, it might be useful to derive lessons from developments in the information systems literature.

Advancing the notion of the informing system as unit of analysis, Cohen (1999) points to challenges of 'silo' thinking within the field of management information systems, as well as to issues of fragmentation and a need to be relevant to practice. Addressing these challenges is particularly important in a global context where theory relating to information systems has over time increased in diversity and complexity (Callaos \& Callaos, 2002), increasing risks of misinforming (Christozov, Chukova, \& Mateev, 2009) and misinformation. Informing the citizen crowd is important, as the quality of any engagement of the crowd is necessarily a function of the quality of information it receives.

According to this perspective, informing disciplines have client populations who it is their duty to inform (Gill, 2009a), and there are certain features of informing science which echo developments in the citizen science movement. These include a focus on informing systems which evolve, or are emergent, with a particular focus on obstacles to informing, such as biases and heuristics. The importance of the message citizen science (Irwin, 1995; 2001) and informing science (Cohen, 1999; Gill \& Cohen, 2009) work conveys cannot be understated; namely, to deal with the complexities of information and knowledge dissemination effectively, stakeholders need to transcend silo limitations of academic fields and engage more effectively with those other stakeholders affected by poor knowledge dissemination.

In much the same way as bioethical engagement requires transdisciplinary theory development and practice, informing science is an example of a field that explicitly incorporates transdisciplinary thought, linking areas such as (but not limited to) psychology, epidemiology, evolutionary biology, and philosophy in pursuit of theory building (Gill \& Cohen, 2008). Similarly, citizen 
science can be taken to reflect the engagement of the populations in research, which by definition presents a boundary spanning role for citizens and the rise of scientific democratisation (Irwin, 2001).

Stakeholders seeking to 'inform' can be at the nexus of multiple informing systems seeking to inform different client populations, leading to tensions between different specialities/disciplines that essentially duplicate efforts at serving client populations, with consequences for both theory and practice (Fitzgerald, 2003). Information systems research needs to be responsive to practitioners and to real-life needs (Fitzgerald, 2003), and movements such as citizen science (Dickinson, Zuckerberg and Bonter, 2010) and informing science reflect perhaps a new awareness of the need to open up 'informing' to broader 'ecological' conceptions of the research landscape.

What is also common between the citizen science and informing science perspectives is an explicit focus on the 'client' in informing science (Gill \& Bhattacherjee, 2007) and the 'citizen' in terms of citizen science, reflecting notions of ethics in information systems (Cohen, 1989) and ethics associated with post-normal science (Funtowicz \& Ravetz, 1994), respectively. Ethics in bioethics, however, are subject to the influence of country legislation, and populations typically receive information from media sources.

Whereas certain countries, including the United States (US), the United Kingdom (UK), Australia, and the Netherlands have centralised review bodies for sGT studies, these bodies have faced criticism for not addressing certain fundamental ethical issues, such as whether it is ethical to modify germ tissues, as well as for simply following conventional processes of safety and consent (Kimmelman, 2008). In the US, the Bioethics Commission, comprised of leaders in science, ethics, law, religion, engineering, and medicine, provides counsel to the President on bioethical issues, drawing inputs from the public and experts (Fenton et al., 2015). Communication of these issues through the mass media may "not only represent scientific concepts and techniques" but also "shape regulatory and ethical frame" (O'Keefe et al., 2015).

The US Recombinant DNA Advisory Committee (RAC) began to play a more comprehensive role in addressing ethical issues and capacitating local review structures and "has a system in place to allow the reporting of adverse events, organises conferences aimed at categorising knowledge on safety or study design, and is committed to almost total public transparency" (Kimmelman, 2008). At the heart of ethics on the 'medical ethics/business ethics' uncertainty frontier seems to be the notion that transparency and the openness of knowledge and information is increasingly important. However, absent from the literature in general is the notion that citizen science and the principles 'crowd-engagement' with these issues should be embedded in the practices of these centralised review bodies. This is the central tenet of this paper; that this citizen science movement needs to be explicitly recognised and incorporated into practices to support business and medical ethical practice. Another important consideration is the speed at which these ethics bodies respond, as evidenced by the slow US response to the Ebola outbreak (Fenton et al., 2015).

Further ethical issues relate to genetic engineering and gene transfer research that are relevant to costs, and the costs facing firms developing these technologies. Kimmelman (2008, p. 240) stresses that gene transfer "has often been characterised as permanently five years away from clinical application." Irrespective of the time frames of radical biomedical innovation, what is required is a focus on strengthening ethics preparedness (Fenton et al., 2015). Ethical challenges associated with the development of gene transfer and its application in clinical practice are primarily related to levels of risk and evidence of novel interventions, and post intervention monitoring also is necessary as side effects can emerge much later (Kimmelman, 2008). Professionalization of the bioethics field, and its educational project (White et al., 2014) are also not independent of time-lines, as they need to keep pace with radical changes in biomedicine. 
Costs are a key dimension of gene research and raise further ethical issues. The development costs of sGT are very high, and this research typically targets orphan diseases, or diseases that are rare, that are typically associated with expensive treatments and expenditures targeted at a onceoff intervention; sGT research is therefore constrained as to its potential availability or access (Kimmelman, 2008). A business case for this research is therefore difficult to make, which gives rise to the business ethics dilemmas faced by society when private firms avoid less profitable avenues of biomedical research. The ethical issues discussed above are compounded when the international context of globalisation is considered.

The context of bioethical engagement with biomedical research has experienced rapid global expansion (Grady, 2013). As mentioned previously, certain cross-national ethical issues also surround the globalisation of sGT, as countries such as China, Brazil, Mexico, and the Philippines are rapidly expanding their programmes; China, for instance, has been reported to have high numbers of "highly cooperative" patients for clinical trials, and "medical tourists" also undergo certain interventions in these countries, notwithstanding the fact that their countries of origin have not approved interventions (Kimmelman, 2008, p. 241). Germline gene transfer (gGT), or the modification of tissues that are passed on to children, poses a host of further ethical issues, which also apply to its use for purposes of both disease elimination and enhancement (Kimmelman, 2008).

Serious gene transfer ethical issues also relate to biosecurity, as many biosecurity processes involve the manipulation of viruses, including in biodefence research, pose serious public health issues, particularly with regard to dual-use genetic applications and issues relating to security and secrecy (Kimmelman, 2008). Without transparency and a widespread (extensive) and critical engagement by all possible stakeholders, a 'Pandora's Box' of uncertain outcomes might be unleashed upon the same stakeholders. Empowering the citizen science movement and embedding its philosophy in oversight forums might be particularly important in these instances. Ethics preparedness is key perhaps to managing these issues as they arise (Fenton et al., 2015).

In the above sections, two examples were used to introduce and illustrate the increasing complexity of certain business/biomedical ethics issues, and the sufficiency of 'conventional' ethical oversight methods were questioned, and used as examples to stress the need for crowd-based, or citizen science engagement in these types of ethical decision making. As an introduction to the arguments made in this paper, these two examples are used by way of an introduction to the context of crowd-based ethical engagement. The commercialisation of human tissues and genetic engineering research were chosen for their salience as extreme examples and their ability illustrate the importance of these arguments. Literature relating to citizen science and 'crowd-based' research is now considered.

Having provided two extreme examples of biomedical research within a context of commercialisation of biomedical science, an argument was made in this paper that rapidly increasing uncertainty associated with research progress necessitates a more inclusive, transparent, and accountable business and scientific ethics-related engagement by stakeholders.

O'Keefe et al. $(2015$, p. 3) stress amidst calls for consensus guidelines on use of techniques, particularly human germ-line applications, most of the public form impressions and opinions derived from mass media sources and from metaphors created by scientists that operate both unconsciously and consciously to "condense and represent formative information in complex linguistic, rhetorical, and psychological ways." Maximised transparency can ensure increased validity in understanding developments, such that it is less likely these channels of communication are appropriated by those with different agendas.

Figure 1 draws its logics from Latour's (2000, p. 117) notions of 'quasi-objects' and the need for convergence in natural and social science foci, from "genetically modified organisms to global 
warming or internet commerce" and the need for social and natural scientists to "forget about what separates them and start looking at those 'things' whose hybrid nature has, for many decades now, already unified them in practice." Arguably, the economic nature of human activity (represented by lines representing different streams of literature in Figure 1) has changed substantively on account of two revolutions in work practice, namely, the industrial and knowledge revolutions, which enabled radically enhanced productivity improvements and a sea change in social theory in their wake. It is suggested here that societal, business, and biomedical ethics are not independent of these changes, and that the post-industrial paradigm, with its ethics premised on social theory developed in response to industrialisation, has been disrupted by a further productivity revolution which has increased the returns to knowledge in production, and that divergence has occurred between ethical thought premised on industrialised logics and a new ethics based on exponential increases in the power of knowledge to generate social and scientific change.

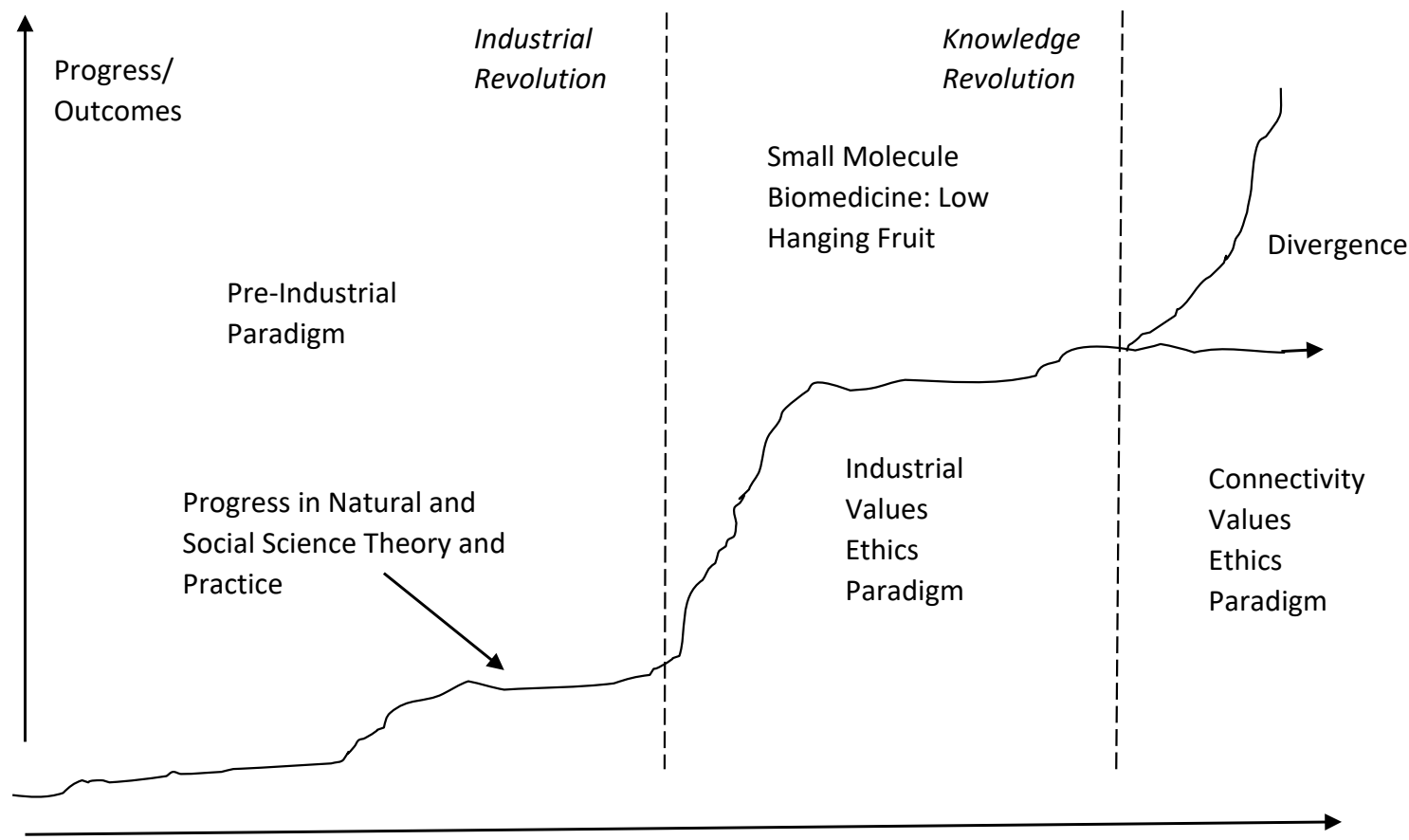

Bedrock Social and Natural Science Theory Growth over time

Figure 1. Plateau and Divergence of Scientific Social and Natural Science Paradigms and Disruptions: Latour's unification paradigm

The emergence of new forms of enterprise, discussed earlier in reference to sale of human tissues, and new forms of biotechnology, such as genetic engineering, are simply examples of this divergence, which arguably requires new thinking around how to radically increase transparency and accountability, as emergent technologies enable not only radically improved potential for innovation but also increasing connectivity between human stakeholders who are directly affected by these developments. This divergence arguably places bioethicists, and education and professionalization of bioethics (White et al., 2014) at the forefront of strategic response to radical advances in biomedicine to come. However, given the uncertainty of 'wicked' problems (Rittel \& Webber, 1973) related to complexity of human values negotiation over increasingly beneficial and hazardous potentialities, the last line of ethical resource might be the democratic population itself. 
Different crowd-based movements associated with the rise of CS such as PLR, PPSR, and postnormal science were then used as examples to argue that their emergence is not only in response to community and stakeholder needs for more timely research outputs in healthcare, but also in response to an increasingly uncertain ethical environment associated with rapid biomedical progress and the need to increase transparency and inclusive stakeholder engagement.

Given the acceleration of biomedical research offered by open innovation, and its inextricable relationships with commercialisation, business ethics issues need to be at the heart of the debate of these issues going forward; business ethics needs to be a full partner with biomedical research ethics as these complex (and potentially dangerous) biomedical developments accelerate.

Bioethical codes of practice (Baker, 2015; Tartzian et al., 2015) may need to be maximally inclusive. Further, it is hoped that over time, the increasingly inclusive paradigm heralded by these movements will challenge the 'chronification' paradigm in biomedical R\&D and result in a 'curative' paradigm, an alignment between the real needs of the crowd and biomedical research outputs. However, because of the persistence of profit incentives for chronification these issues fall squarely into the realm of business ethics theory and practice, and work such as this represents a 'call to arms' around these issues for the business ethics field.

What is needed, however, is also a focus on scientific dissemination of information, as populations not aware of these developments will be unable to play a role in holding business and biomedical research to account. Citizen science fits within the principles of informing science (Cohen, 1999; Gill \& Cohen, 2009) in that informing science proposes a fundamental role for boundary spanning, and addressing 'silo' knowledge structures, or the dismantling of 'firewalls' that separate disciplines of science (informing science), or that separate populations affected by science from participating on the front line of science itself (citizen science).

Improving efforts to inform clients (conceptualizing stakeholders as client populations), and providing them with information in a more effective form, format, and schedule that maximises effectiveness (Bednar \& Welch, 2008, 2009; Cohen, 1999; Gill, 2009a) is perhaps key to enabling citizen crowds to engage with biomedical issues that affect them.

\section{Implications and Recommendations}

On the basis of the analysis in the above sections, Figure 2 summarises theory and arguments into (i) first-level theory recommendations, and (ii) second-level practice recommendations that link the literature to citizen science logics and the goal of maximising bioethical transparency and accountability. Overall, certain useful implications can be derived, which relate directly to democratisation of science movements. Firstly, it is recommended a culture of immediacy be developed around bioethical response, both to developments in biotechnology and well as toward inaction on the part of research stakeholders, or slow research response to societal problems. An example of improved bioethical response is the use of open peer commentaries in scholarly journals (Magnus et al., 2014), which can deepen the immediacy of engagement with bioethical issues in a way that matches rapid developments, particularly in health disasters and threats to populations (Fenton et al., 2015) which require real time response. 


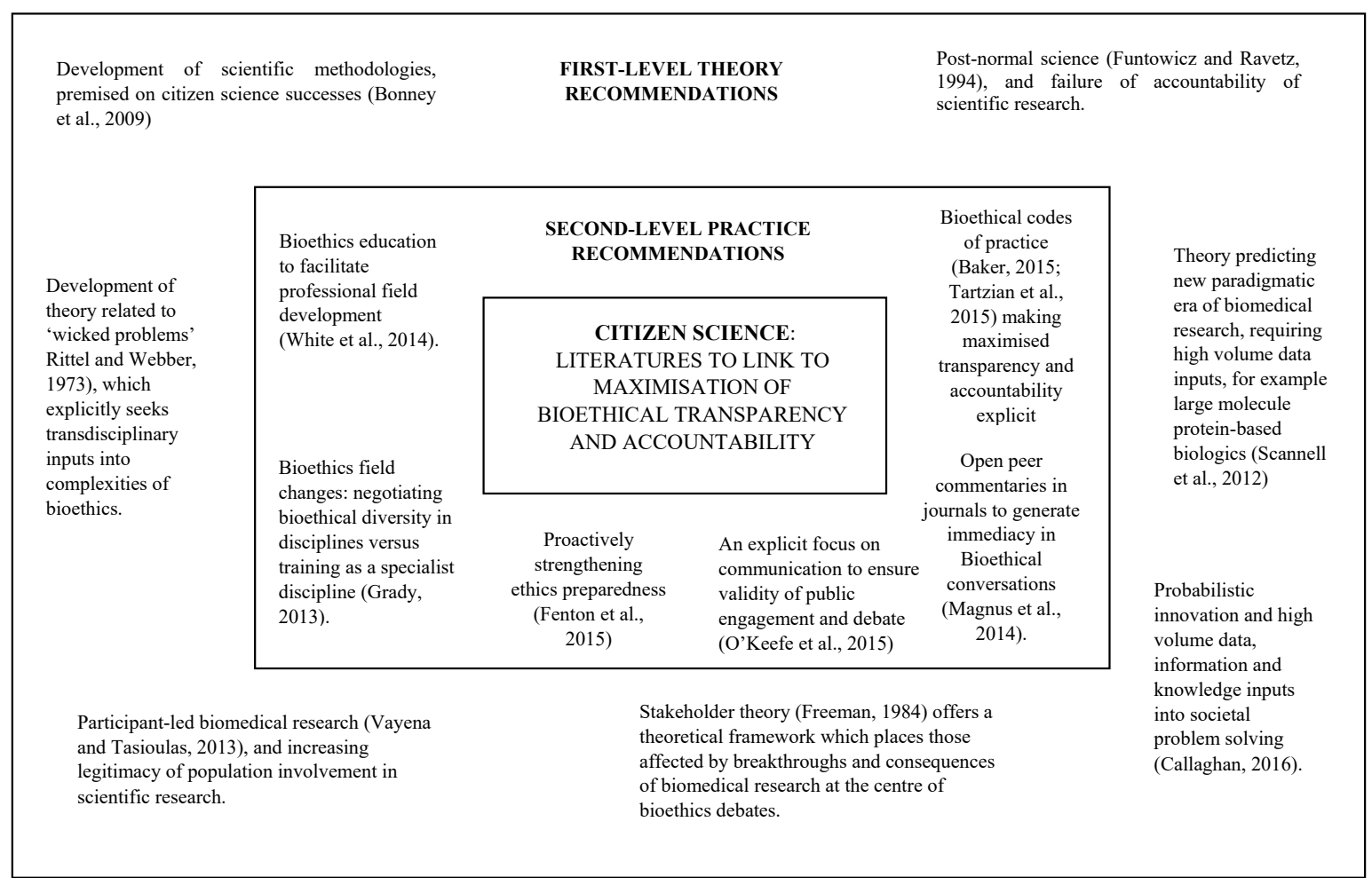

Figure 2. Applications of Citizen Science principles to Bioethics

Second, deepening of institutional structure should be an ongoing project, particularly as it relates to bioethical codes (Baker, 2015; Tartzian et al., 2015), as well as proactive institutional engagement to improve responsiveness (Fenton et al., 2015). Institutional engagement with the future of the bioethics field is required to steward professionalism (White et al., 2014) and populate the health professions with those trained in bioethics, given radical changes in biomedical research and practice to come (Grady, 2013). This is particularly important given the rise of Big Data, as well as new biomedical methodologies such as crowdsourcing applied to biomedical research (Callaghan, 2014a; 2014b).

Third, explicit engagement with issues relating to channels of communication around biotech developments is needed, in order to ensure narratives are not 'captured' by those with agendas (O'Keefe et al., 2015) and validity of public knowledge is ensured through development of appropriate biomedicine vocabularies. These practical initiatives capture the spirit of citizen science theory (Bonney et al., 2009) in terms of increasing responsiveness of populations to issues which affect them, or democratisation of both scientific discovery and its scrutiny. Theory related to wicked problems, or problems at the nexus of human values and uncertainty (Rittel \& Webber, 1973), together with citizen science theory may help bioethicists negotiate changes to come in the biomedical research landscape.

Fourth, theory building requires synthesis of different literatures which advance the same goal, namely, to empower the crowd to engage with important scientific issues such as genetic engineering, human tissue market development, and other important biomedical research outcomes. This entails a need to build synergies between citizen science theory and other bodies of theory such as informing science, which offer an emergent body of research specifically focused on informing stakeholders. 
Stakeholder theory (Freeman, 1984) provides a further theoretical rationale for the voices of those affected by lack of scientific progress as well as the consequences of biomedical research to be included in bioethical conversations.

Arguably, the democratisation of bioethics engagement comes none too soon, as recent developments in the wake of the Ebola outbreak have highlighted the importance of a re-configuration of bioethics institutions to meet requirements of agility in response to public emergencies (Fenton et al., 2015). Recent ethics deliberations in the wake of public health emergencies such as the Ebola outbreak have also affirmed the deliberative democratic approach with maximised real time stakeholder engagement in research and policy making, and the need for proactive democratic deliberation in advance of such events (Fenton et al., 2015). Recently the US Bioethics Commission facilitated a two-day public meeting to bring together stakeholders and public participation to guide its ethics response to Ebola, captured in the document 'Ethics and Ebola,' which according to Fenton et al. (2015, pp. 77-78):

[A]rticulates a vision for ethics preparedness for public health emergencies that encompasses proactive democratic deliberation and public engagement; effective, accurate, and transparent communication in advance of and in the midst of emergencies; ethics integration throughout the emergency planning ad response life cycle; and commitment to the ethical principle of least infringement in relation to public health interventions such as quarantine...public and even expert debate in times of crisis can devolve into battles among ideologies, with support for different forms of response dividing along partisan lines...One of the central ethical challenges of preparing for and responding in real time to public health emergencies is to navigate conflicting values...A deliberative democratic approach to decision making encourages stakeholders to come to the table willingly to economize on moral disagreement and to seek policies which converge, even if different values are invoked to support them. Both proactive democratic deliberation in advance of public health emergencies and, and open and transparent public engagement in real time during an emergency are critical to public health planning and response.

Given longstanding critique of lack of accountability of scientific research (Funtowicz \& Ravetz, 1994), tenets of post-normal science provide a grounding for research in the form of maximised transparency and scrutiny by populations themselves, but these movements coincide with theory predicting fundamental changes in science and scientific research itself (Scannell et al., 2012), also enabled by technological developments which may exponentially increase the potential for research collaborations, which might in turn have important implications for disaster management and real time scientific research (Callaghan, 2016a; 2016b). In a world in which biomedical breakthroughs may ultimately occur more rapidly, more specific research is needed so as to prepare the way through proactive bioethics engagement, perhaps harnessing the same democratisation mechanisms as those which have spurred current advances.

\section{Conclusions}

Given recent developments in bioethics literature in the wake of the Ebola crisis and a call for more responsive bioethical engagement with medical crises in real time, the objective of this paper was to provide a synthesis of literature and an argument for radically enhanced stakeholder inclusivity in bioethics governance of biomedicine. Central to the notion of radically enhanced stakeholder inclusivity is engagement of populations, and the rise of citizen science reflects increasing engagement of stakeholder populations in the practice and scrutiny of science itself. Certain examples, such as increasing commercialisation of human tissues and radical advances in genetic engineering, were used as heuristics to frame these discussions. The contribution of this paper is its recognition of new developments in citizen science, which are particularly salient given the rise of the big data era of data analytics and increasing biomedical research capabilities in 
the midst of political and social societal influences that together reflect a milieu of increasing uncertainty in biomedicine. In addition to a synthesis of literatures, the paper highlighted how the industrial era ethics paradigm might be incommensurate with new knowledge-based biomedical ethics needs and presented an argument that maximised transparency and scrutiny roles be extended to stakeholders as this mechanism might be an important safeguard in a time where political interference and profit essentialism in biomedicine may not adequately reflect the interests of stakeholders. Citizen science was offered as a useful source of theory development for biomedical ethics going forward, and the contributions of other movements, such as informing science, which have emerged in tandem with the citizen science movement, were also highlighted for their potential contribution to this end. Recommendations were differentiated on the basis of theory and practice; 'first level' theory recommendations were made, offering insights into a growing body of theory useful for bioethics theory development, and 'second level' recommendations were made for practice, derived from these bodies of literature. It is hoped further theory development and practice in bioethics can keep pace with the radical changes spurred by technological developments, and that stakeholder inclusivity is not ultimately marginalised in a world of accelerating biotechnological innovation.

\section{References}

Baker, R. (2015). The significance of the ASBH's code of ethics for healthcare ethics consultants. The American Journal of Bioethics, 15(5), 52-54.

Bednar, P. M., \& Welch, C. (2008). Bias, misinformation and the paradox of neutrality. Informing Science: the International Journal of an Emerging Transdiscipline, 11, 85-106.

Bednar, P. M., \& Welch, C. (2009). Inquiry into informing systems: Critical systemic thinking in practice. In T. G. Gill. \& E. B. Cohen (Eds.), Foundations of informing science: 1999-2008 (pp. 459-502). Santa Rosa, CA: Informing Science Press.

Bonney, R., Cooper, C. B., Dickinson, J., Kelling, S., Phillips, T., Rosenberg, K. V., \& Shirk, J. (2009). Citizen science: A developing tool for expanding science knowledge and scientific literacy. BioScience, 59(11), 977-984.

Burrel, G., \& Morgan, G. (1979). Sociological paradigms and organisational analysis. London: Heinemann.

Callaghan, C. W. (2014a). Solving Ebola, HIV, antibiotic resistance and other challenges: The new paradigm of probabilistic innovation. American Journal of Health Sciences, 5(2), 165-178.

Callaghan, C. W. (2014b). Crowdfunding to generate crowdsourced R\&D: The alternative paradigm of societal problem solving offered by second generation innovation and R\&D. The International Business \& Economics Research Journal, 13(6), 1499-1514.

Callaghan, C. W. (2015). Crowdsourced 'R\&D' and medical research. British Medical Bulletin, 115(1), 6776.

Callaghan, C. W. (2016a). Disaster management, crowdsourced R\&D and probabilistic innovation theory: Toward real time disaster response capability. International Journal of Disaster Risk Reduction, 17, 238-250.

Callaghan, C.W. (2016b). A new paradigm of knowledge management: Crowdsourcing as emergent research and development. Southern African Business Review, 20, 1-28.

Callaos, N., \& Callaos, B. (2002). Toward a systemic notion of information: Practical consequences. Informing Science: The International Journal of an Emerging Transdiscipline, 5(1), 1-11.

Chesbrough, H. (2011) Pharmaceutical innovation hits the wall: How open innovation can help. Forbes. Retrieved April 11, 2015, from http://www.forbes.com/sites/henrychesbrough/2011/04/25/pharmaceutical-innovation-hits-the-wallhow-open-innovation-can-help/ 
Christozov, D., Chukova, S., \& Mateev, P. (2009). Informing processes, risks, evaluation of the risk of misinforming. In T. G. Gill. \& E. B. Cohen (Eds.), Foundations of informing science: 1999-2008 (pp. 323356). Santa Rosa, CA: Informing Science Press.

Cohen, E. (1989). A question of ethics: Developing information system ethics. Journal of Business Ethics, $8(6), 431-437$.

Cohen, E. (1999). Reconceptualizing information systems as a field of the transdiscipline. Journal of Computing and Information Technology, 3, 213-219.

Datamonitor Healthcare. (2014). New HIV drug to become leading treatment by 2016. Retrieved June 21, 2015, from http://www.datamonitorhealthcare.com/new-hiv-drug-to-become-leading-treatment-by2016/

Dickenson, D. (2009). Good science and good ethics: Why we should discourage payment for eggs for stem cell research. Nature Reviews Genetics, 10(11), 743.

Dickinson, J. L., Zuckerberg, B., \& Bonter, D. N. (2010). Citizen science as an ecological research tool: Challenges and benefits. Annual Review of Ecology, Evolution and Systematics, 41, 149-172.

Döring, O. (2003). China's struggle for practical regulations in medical ethics. Nature Reviews. Genetics, 4, 233-239.

Fenton, E., Chillag, K., \& Michael, N. L. (2015). Ethics preparedness for public health emergencies: Recommendations from the Presidential Bioethics Commission. The American Journal of Bioethics, 15(7), 77-79.

Freeman, R. E. (1984). Strategic management: A stakeholder approach. Boston: Pitman.

Fitzgerald, B. (2003). Informing each other: Bridging the gap between researcher and practitioners. Informing Science: The International Journal of an Emerging Transdiscipline, 6, 13-19.

Funtowicz, S. O., \& Ravetz, J. R. (1994). Uncertainty, complexity and post-normal science. Environmental Toxicity and Chemistry, 13(12), 1881-1885.

Gill, T. G. (2009a). An open letter to the Informing Science Community. Informing Science: The International Journal of an Emerging Transdiscipline, 12, v-x.

Gill, T. G. (2009b). Routine vs. non-routine Informing: Reflections on what I have learned. In T. G. Gill. \& E. B. Cohen (Eds.), Foundations of informing science: 1999-2008 (pp. 739-766). Santa Rosa, CA: Informing Science Press.

Gill, T. G. (2011). When what is useful is not necessarily true: The underappreciated conceptual scheme. Informing Science: The International Journal of an Emerging Transdiscipline, 14, 1-32.

Gill, T. G., \& Bhattacherjee, A. (2007). The informing sciences at a crossroads: The role of the client. Informing Science: The International Journal of an Emerging Transdiscipline, 10, 17-39.

Gill, T. G., \& Cohen, E. B. (2008). Research themes in complex informing. Informing Science: The International Journal of an Emerging Transdiscipline, 11, 147-164.

Gill, T. G., \& Cohen, E. B. (2009). Foundations of informing science: 1999:2008. Santa Rosa, CA: Informing Science Press.

Grady, C. (2013). Reflections on two decades of bioethics: Where we have been and where we are going. The American Journal of Bioethics, 13(1): 8-10.

Hayden, E.C. (2014). Technology: The \$1,000 genome. Nature, 507, 294-295.

Irwin, A. (1995). Citizen science. Vol. 136. London: Routledge.

Irwin, A. (2001). Constructing the scientific citizen: Science and democracy in the biosciences. Public Understanding of Science, 10(1), 1-18.

Kaitin, K. (2010). Deconstructing the drug development process: The new face of innovation. Clinical Pharmacology and Therapeutics, 87(3), 356-361. 
Kimmelman, J. (2008). The ethics of human gene transfer. Nature Reviews Genetics 9, 239-244.

Kuhn, T. S. (1962). The structure of scientific revolutions. Chicago, Il: University of Chicago Press

Latour, B. (2000). When things strike back: A possible contribution of 'science studies' to the social sciences. British Journal of Sociology, 51(1):107-123.

Lim, S. Y. L., \& Suh, M. (2015). Product and process innovation in the development cycle of biopharmaceuticals. Journal of Pharmaceutical Innovation. Retrieved April 9, 2015, from http://downloadv2.springer.com/static/pdf/569/art\%253A10.1007\%252Fs12247-015-92149.pdf? token $2=\exp =1428557508 \sim$ acl $=\% 2$ Fstatic $\% 2$ Fpdf $\% 2 \mathrm{~F} 569 \% 2 \mathrm{Fart} \% 25253 \mathrm{~A} 10.1007 \% 25252 \mathrm{Fs} 12$ 247-015-92149.pdf* hmac $=56205 \mathrm{~d} 99 \mathrm{cfc} 46551 \mathrm{~b} 0 \mathrm{~d} 1 \mathrm{~b} 47 \mathrm{~d} 147 \mathrm{~d} 6 \mathrm{da} 3275 \mathrm{~b} 0 \mathrm{~d} 42515796508018 \mathrm{c} 22 \mathrm{cc} 55 \mathrm{fcd} 78$

Magnus, D., Parsi, K., \& Sharp, R. (2014). A JOB 2.0: Taking bioethics to a new level. The American Journal of Bioethics, 14(8), 1-2.

Mandal, J., Ponnambath, D. K., \& Parija, S. C. (2016). Utilitarian and deontological ethics in medicine. Tropical Parasitology, 6(1), 5-7.

O'Keefe, M., Perrault, S., Halpern, J., Ikemoto, L, Yarborough, M., \& UC North Bioethics Collaboratory for Life \& Health Sciences. (2015). "Editing" genes: A case study about how language matters in bioethics. The American Journal of Bioethics, 15(12), 3-10.

Rittel, H. W. J., \& Webber, M. M. (1973). Dilemmas in a general theory of planning. Policy Sciences, 4, 155-169.

Scannell, J. W., Blanckley, A., Boldon, H., \& Warrington, B. (2012). Diagnosing the decline in pharmaceutical R\&D efficiency. Nature Reviews Drug Discovery, 11, 191-200.

Shirk, J. L., Ballard, H. L., Wilderman, C. C., Phillips, T., Wiggins, A., Jordan, R.,... Bonney, R. (2012). Public participation in scientific research: A framework for deliberate design. Ecology and Society, 17(2), 1-29.

Tarzian, A. J., Wocial, L. D., \& The ASBH Clinical Ethics Consultation Affairs Committee. (2015). A code of ethics for health care ethics consultants: Journey to the present and implications for the field. The American Journal of Bioethics, 15(5), 38-51.

Vayena, E., \& Tasioulas, J. (2013). The ethics of participant-led biomedical research. Nature Biotechnology, 31(9), 786-787.

Wertz, D. C. (2002). Embryo and stem cell research in the United States: History and policy. Gene Therapy, 9(11), 674-678.

White, B. D., Jankowski, J.B., \& Shelton, W. N. (2014). Structuring a written examination to assess ASBH health care ethics consultation core knowledge competencies. American Journal of Bioethics, 14(1), 517 .

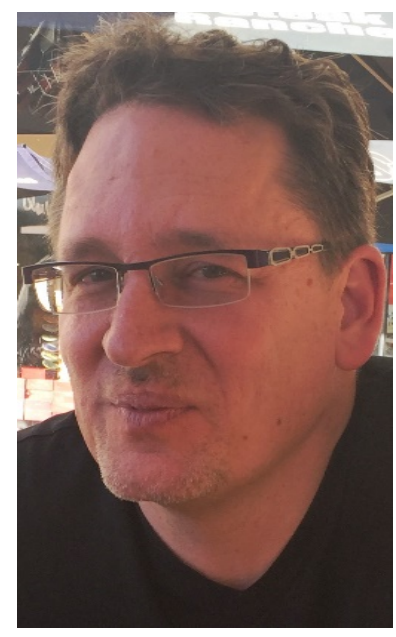

\section{Biography}

Chris William Callaghan is an Associate Professor in the School of Economic and Business Sciences of the University of the Witwatersrand, in Johannesburg, South Africa. His is founder and Director of the Knowledge and Information Economics/Human Resources Research Agency (KIEHRA). A key stream of his research relates to how information and knowledge can be better used to solve serious societal problems. Key to this is developing theory around how connectivity and collaborations between researchers can be maximized to enable accelerated problem solving, and to harness human collective intelligence in support of socially important innovation. 